\title{
The Impossible Decision: Social Tagging and Derrida's Deconstructed Hospitality
}

\author{
Melodie J. Fox* and Austin Reece** \\ *University of Wisconsin-Milwaukee, School of Information Studies, \\ PO Box 413, Milwaukee, WI 53201, USA, <msjoblad@uwm.edu> \\ **Marquette University, Department of Philosophy, \\ PO Box 1881, Milwaukee, WI 53201, <austin.reece@marquette.edu>
}

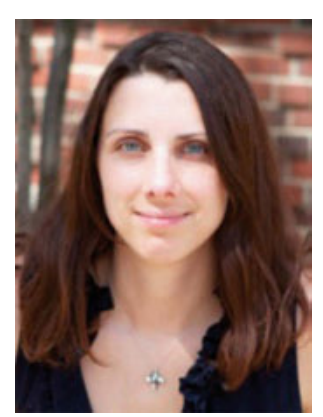

Melodie J. Fox is a doctoral candidate at the University of Wisconsin-Milwaukee's School of Information Studies, where she also earned an MLIS, and is a member of the Information Organization Research Group there. She also holds a master's in English from the University of Illinois-Chicago. Her research interests include the relationship between epistemology and subject access, with a particular interest in the categorization of race and gender.

Austin Reece is currently a Ph.D. candidate in philosophy at Marquette University. He holds a master's in contemporary European philosophy from University College Dublin and a bachelor's in philosophy from Boston College. His research interests include philosophy of religion and ethics.

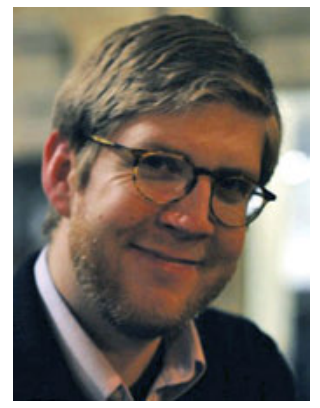

Fox, Melodie J. and Reece, Austin. The Impossible Decision: Social Tagging and Derrida's Deconstructed Hospitality. Knowledge Organization. 40(4), 260-265. 14 references.

ABSTRACT: Social tagging has been lauded for providing a voice of the user community, free of restrictions dictated by knowledge organization standards for subject access. Tagging allows many perspectives to be represented, but at what cost? Using deconstruction, Derrida argues that absolute hospitality is required to ensure justice for access and inclusiveness; however, the consequence becomes that the host becomes hostage to the other. In this ongoing research, we explore the Derridean concept of hospitality as it relates to social tagging, examining the consequences of unconditional inclusiveness, the process of discerning constraints to hospitality in order to interpret different kinds of "otherness" — or what Derrida calls the "impossible" decision—and what mitigation means, using the social tagging environment to illustrate.

Received 9 May 2013; Accepted 9 May 2013

\subsection{Introduction}

The recent explosion of epistemological research in knowledge organization (KO) signifies a transition from a universalist paradigm as envisioned by modern classificationists such as Dewey, Sayers, Richardson, and Bliss, to a postmodern paradigm, one where the social and contextual nature of knowledge is acknowledged. In the new paradigm, researchers imagine myriad user- or discourse community-centered knowledge organization systems (KOS's) rather than the singular, objectivist 'god's eye view' classifications that ostensibly mirror reality (Mai 2004). An obstacle for the postmodern interpretation of knowledge or- ganization is bibliographic control: How can KOS's be inclusive but remain organized for retrieval? How can systems avoid oppressing through conceptual or structural violence? Whose reality is the classification reflecting? One solution has been to supplement formal KOS's with social tagging to provide a forum for users' voices. To explore the ethical implications of this pairing, we look to poststructuralism, and specifically Jacque Derrida's deconstruction of the concept of hospitality, as it applies to social tagging. As a clarification, we refer to the traditional definition of hospitality, not the concept of hospitality as it is currently used in classification, i.e., structure that easily absorbs new concepts. In a previous work, we reviewed a se- 
lection of ethical frameworks, including the Derridean interpretation of hospitality, for applicability to KO. We presented a model of ethical principles that information professionals can use as a framework for decision-making (Fox \& Reece 2011, 381). One of the criteria chosen for this model was hospitality with mitigation. In this ongoing research, we explore the Derridean concept of hospitality more closely, examining the consequences of unconditional inclusiveness, the process of discerning constraints to hospitality in order to interpret different kinds of "otherness" - or what Derrida calls the "impossible" decision (Derrida and Dufourmantelle 2000, 75) — and what mitigation means, using the social tagging environment to illustrate. First, we will provide a brief description of deconstruction in order to help understand how Derrida arrives at his concept of hospitality. Then, we will describe how deconstructed hospitality relates to knowledge organization in general and social tagging specifically, using examples from LibraryThing and Flickr. Finally, we will discuss the notion of discernment and to what degree that mitigation is evident or not in social tagging environments and the consequences of such mitigation.

\subsection{Deconstruction and différance}

Derrida's interpretation of hospitality is deconstructed, and therefore a rudimentary understanding of deconstruction is necessary. Derrida suggests that everything, including human consciousness and language, is "deconstructible," so that deconstruction happens everywhere whether or not we can see it (Kearney 2004, 167). Deconstruction requires a certain way of "reading" the "text" or "context." By "text," Derrida does not mean merely a piece of writing contained in a physical medium like a book. All experience, anything that "is," is structured by a kind of textuality (Derrida 1976). The root form of "text" comes from the classical Latin textus, or "that which is woven" $(O E D)$. Anything present that gives us something to view is woven together. What seems to provide a minimal "sameness" is always already dependent on an element of "difference." This dependence of presence on absence, sameness on alterity [otherness], ultimately defers or postpones the possibility of grasping something in its entirety. This double sense of differ/defer inspires Derrida (1988) to coin the neologism "differrance" to describe the workings of textuality. Différance "cannot be reduced to the stable determination of that which is 'different;' or, in other words, it cannot be unproblematically reduced to the range or field of differences which it originally makes possible" (Wortham 2010, 29). Despite his broad idea of “text," Derrida's career was defined by close readings of actual texts. Critchley and Mooney $(1994,443)$ summarize his style as "dou- ble reading," by "first repeating what Derrida calls 'the dominant interpretation' and then opening a text up to the blind spots or ellipses within [it]." Derrida's double reading simultaneously opens the dominant interpretation of a text to its repressed other.

Deconstruction has been recommended and used by Olson $(1995 ; 1997 ; 2002)$ as a methodology for scrutinizing both knowledge organization standards and the binary oppositions that exist both in $\mathrm{KO}$ principles and more widely in LIS. Olson $(1997,181)$ recommends deconstruction "for identifying and questioning underlying theoretical assumptions" in both the principles of knowledge organization and in the structure and components of knowledge organization systems. Following Lather, she operationalizes deconstruction to the following three steps:

1. Identifying the binary;

2. Reversing/decentering the binary;

3. Dissolving the binary (Olson 1997, 182).

The result of deconstruction is that the constructed quality of concepts is laid bare, the oppressed other is revealed, and the opposition between them dissolved so that neither aspect of the binary is privileged, and a more ethical relationship can be formed. As Derrida states, "Deconstruction is not an enclosure in nothingness, but an openness towards the other" (cited in Kearney 2004, 173).

\subsection{Hospitality, hostility and knowledge organization}

In the dominant or traditional interpretation of hospitality, the sovereign master of the "home" sets the rules and conditions of a guest or stranger (xenos) entering and abiding in the home. As the owner of the property, the sovereign is allowed to "police the threshold" and decide what is proper and improper, who is in or out. In relation to one's self and autonomy, Derrida argues that who or what is other must have their singularity respected so that their difference is not coerced and coopted by any system of control. When considering concepts rather than people, a phenomenon is, by definition, that which appears and reveals itself to human consciousness, whether through perception, conception or imagination. An enigma, by contrast, remains hidden and concealed, barring itself from the reaches of the human mind in its attempts to know. The other signifies the enigmatic in all its puzzling opacity and is thus anti-phenomenological. In other words, the other is impossible to know because any method of discernment is inadequate to the enigma. Who or what is enigmatically other? The other obligates us from the outset; there is always an other before whom or 
to whom one must answer and respond. Only in this answering can the subject take shape. To put it in a slogan: subjectivity is responsibility to the other. The self is always already beholden to the other. Genuine hospitality must be absolute and unconditional. Ideally, every other must be welcome across the threshold into the system/category. In reality, everyone is seen as a potential threat or menace, so we always set limits on who is welcome. However, every time a constraint is put in place, a door closes for someone. Such closure should be regarded with suspicion, as it removes the possibility of inclusiveness. In some cases, though, what is precisely outside the law, rule, or code is what is ethical or right in a truer sense. With the risks in mind, Derrida argues that only unconditional hospitality opens real world possibilities for inclusion and justice (Derrida and Dufourmantelle 2000).

In knowledge organization, the standards that govern bibliographic control constitute the laws that "police the threshold," controlling everything including vocabulary, structure, category borders, aboutness, and "other" interpretations of meaning and content. Standards practice what is considered a necessary form of censorship to keep out misspellings, subjectivity, non-dominant interpretations, or other differences. As Olson (1997, 187) warns, "Applying universal standards risks excluding Others." Derrida argues that this approach co-opts methods of violence: conceptual, ethical, and sometimes physical (Derrida and Dufourmantelle 2000). The enactment of the sovereign's right of power over the stranger/guest/other reinforces a hierarchy or system of power and demands that the xenos submit to those limits or be excluded. A well-known example is DDC's 200 class, where Christian topics occupy most of the class, and the rest of the world's religions-including the largest, Islam—are crammed into 290. To be included is to submit to conditions. Hospitality, which typically carries a genial connotation, quickly morphs into hostility when deconstructed, namely, into xenophobia. Though xenophobia seems extreme, many examples can be found in past and present bibliographic standards, and are identified in such works as Berman's (1993) Prejudices and Antipathies, Olson's (2002) The Power to Name, and in industry or government classifications (Bowker and Star 1999).

A radical passivity and vulnerability of the host/home is inherent in the process of inclusion and exclusion. Inside and outside become inextricable-one is both host and hostage; one is both guest and enemy. Things are never certain or safe; binary logic doesn't capture the reality of hospitality. A genuine risk exists that a gracious host/sovereign will become hostage to a guest that acts in violation of the conditions of the home. The unanticipatable arrivant can explode norms and defy rules, for better and for worse, which illustrates nicely the ambiguous nature of an "outlaw," so to speak. This threat of becoming a hostage turns the once-welcoming threshold to stone and closes off entry. Mutual exclusivity, for one, constitutes a stone threshold that cannot be breached by outlaws.

\subsection{Social tagging: Unconditional hospitality}

Social tagging, while flouting bibliographic control, can be considered an ethical addition to $\mathrm{KO}$ in that it practices unconditional hospitality to the other as recommended by Derrida. For example, on the website LibraryThing (www.librarything.com), where virtual "books" are tagged, the website's authors attempt to show how they are subverting the rules of the library world: "Tags are a simple way to categorize books according to how you think of them, not how some library official does." The result is an unregulated mishmash tag cloud of personal ("borrowed from Janel"; “*L"), descriptive ("hardcover"), genre ("short stories"), subject ("scarecrows"), affective ("horrible"), and taskoriented tags ("to-read"), open to any perspective or whim. Additionally, LibraryThing is hospitable to foreign words and phrases, numbers, and sentence-long tags. Photosharing website Flickr (www.flickr.com), on the other hand, emphasizes the social and classificatory aspect rather than the personal: 'You can give your uploads a 'tag,' which is like a keyword. Tags help you find things which have something in common." Tags on Flickr can only be applied once, and only 75 unique tags can be applied to each photo, whereas LibraryThing tags are unlimited.

Because of Derrida's mandate for ultimate hospitality, a concept becomes a shifty thing, suffering from permanent incompleteness. Similarly, taggers provide the voice of the other as desired by the host; however, they may misrepresent the content of a work, by mistake or with intention; misspell; provide conflicting, offensive, or incoherent information, which eliminates the possibility of stable "sameness" or consensus of "aboutness." Violence occurs at the edge of categories, if any categories exist, because of the personal, subjective, and unregulated nature of tags. Dominant and non-dominant viewpoints can be rendered indistinguishable, leaving it to the self or subject to determine. What do we make of the conflicting tags for Dan Brown's The Da Vinci Code, such as "crap" (45 instances as of 25 April 2013) and "good" (5 instances). Is The Da Vinci Code "Christian" (13 instances) or "Anti-Christian" (8 instances)? The following two tags of The Hunger Games illustrate both enigmatic opposition and a violation of normative tagging rules: "I'm not sure how to describe it... but it's one of the best books I've ever read," or "it is totally without any redeeming quality. It is about 12 children picked to kill each other until only one is left alive."

So then, in cases of conflicting information, which is the other? Derrida states that every other "reciprocally contaminates" every other it comes into contact with so that 
neither emerges unscathed (Kearney 2004, 171). The infinite task is to minimize the harm that comes from contamination in the form of subordination and prejudice, or, the dissolution of the binary. This "contamination" occurs when approaching the other with unfamiliarity, fear, and uncertainty. Unless that other is answered to, the fear remains, contaminating the self with suspicion, anger, or distain. Otherwise harmless tags can be treated with apprehension and ultimately xenophobia. The unknown and unfamiliar can be anything: a personal tag, a tag in a foreign language, a tag expressing the opposite opinion held by the subject, or a tag that does not follow the "rules" of tagging. For instance, the term kaunokirjallisuus occurs in nearly 10,000 instances on LibraryThing. For those unfamiliar with the word, trepidation can accompany the encounter with this tag not only because of its unfamiliarity, but also its frequency. To reduce the fear, "answer to" this other, and dissolve the binary, kaunokirjallisuns, as other, must be approached and examined. Once it is determined that it simply means "fiction" in Finnish, the xenophobia and suspicion decrease. It could be as simple as translating a foreign word to remove the uncertainty, accepting a differing opinion, realizing a mistake has been made or researching an acronym.

At times, unconditional hospitality can hold the host hostage with intention. On Flickr, for example, the 20 "hot tags" for the 24 hour period prior to April 5, 2013, included modestdamadresses, shortdamadresses, maternitydamadress, cheapdamadress, juniordamadress, plussizedamadresses, dressesunder100, etc. The tagged photos have nothing to do with dresses, but alongside the photos advertisements for dresses display prominently. Clearly the hospitality allowed by the photographers was being exploited by a commercial xenos, unless they were complicit. Additionally, no agency exists on LibraryThing for those who are more apt to be held hostage by hospitality: authors. Their vulnerability allows opportunity for both risk and reward. What authors wants their work to garner the tags "drivel" or "god awful waste of time?" Yet the risk is that the work might also be tagged "brilliant" or "loved it." For the site, the risk of unconditional hospitality is to be considered a site that attracts spam or where a negative or commercial vibe prevails.

\subsection{Discernment: The "impossible decision"}

The main concern, then, is the task of discernment, or the process of deciding who or what is allowed to cross the threshold precisely when the ideal is to let every other come. If others are granted agency and humanity, then the type of rational discernment necessary in this situation would need to be attuned to those others as subjects that can always be unpredictable. Every other must respond to all others with hospitality bent on perfection, ceaselessly interrogating and challenging its own concepts and categories to minimize harm and let the other be. This is the ethical exigency to be responsible to the other even if it requires a limit to what we desire, namely, control, security, and a future we can calculate and predict. In the context of social tagging, concrete hospitality would need to be based on consent rising from local perspectives that aim for openness and "common" agreement (an endless task), and not rigid norms being imposed from above that claim to be "universal" (which may lead to an insurrection of users who find their agency restricted and their kind of other-ness excluded). As Derrida argues, there can be no "transcendental criteriology" (Kearney 2004, 169). By this, he means that the criteria must originate microlocally, not externally, as it does in knowledge organization standards.

The tagging sites engage in the act of discernment, or set the rules for hospitality. When it comes to explicit statements of hospitality, sites tend to speak out of both sides of their mouths. For example, the terms of use state, "LibraryThing has no speech code. You can dispute ideas and words without limitation," but then goes on to give "Good Advice" and "Other Rules" which exemplify the "discernment" or mitigation of the host. Similarly, Flickr asks users to "Do play nice. We're a global community of many types of people, who all have the right to feel comfortable and who may not think what you think, believe what you believe or see what you see. So, be polite and respectful in your interactions with other members." Asking users to be respectful both limits and accepts the full representation of viewpoints. This guidance tends to apply mostly to reviews, as the tags themselves do not appear to be monitored. With no flagging mechanism for tags, no tag is privileged, other than through frequency. Members of Flickr may report such activity as "phishing" or "Spam-o-rama," but the onus is on users to report and a final decision is made by the site, a controlling system.

To look at some concrete examples of nondiscernment, LibraryThing tags include what can be considered profane and offensive tags, such as "shitty," or "boring as fuck," and "cunt." In Flickr, for instance, the tag "nigger," has been applied to 8,000 photos without apparent censorship. In terms of Derridean hospitality, censorship would close off entry to other uses of such words by those-despite disopprobrium in dominant societywith colloquial, historical, or "reclaimed" usages. They may be considered other to the majority, but not to all. The dominant and non-dominant usages and other contextual, personal, and cultural details make up the textus of the tag. Therefore, the effort required and threshold of hospitality, or the ceaseless interrogation, of the users that encounter such incidents determines the fate of the violators. To understand the full context of the tag- 
interpreted-as-offensive, one must patiently pursue all the strands of potential meaning that exist heteronomously to the subject's perspective. This requires careful and open-minded reading and the bracketing out of the assumption that one knows in advance exactly what was meant by the tag.

LibraryThing offers methods of mild mitigation in its "tagmash" and "tag combination" features. Tagmashes combine tags to make them more accurate. For example, books listed with the tag 日本語, which means "Japanese," are actually written in English, but they are about the Japanese language. Therefore, a "related tagmash" is "Japanese" and "Language." In this way, LibraryThing attempts to "correct" the users' tags without disturbing them. Users can also suggest "tag combinations," which allows for variations in form of the same concept. The proposed combinations are posted on a page and members can vote whether to combine them or not. This makes the likely accurate and useful assumption that such tags as "coudl not put down" and "could not put down" indicate the same concept. According to unconditional hospitality, they are two, as they represent two potentially different concepts. Members vote and must meet an 8-vote advantage threshold in order for tags to be collapsed together. While some combinations seem failsafe, such as "cat breeds" and "Feline Breeds," as of 25 April, still six members voted against the change (with nine votes for). Though it is a democratic process, is it hospitable? Derrida would say no-any votes against make the decision impossible as a door-closing constraint.

Similar examples of categorical violence can be found on LibraryThing. For example, for the book The Hunger Games, as of April 2013, 454 attempts to convey the concept of "post-apocalyptic" subsumes 25 unique tags, including "post apocolypic" and "post-apocalptic," yet while we can assume that those two tags, along with others like "post apocalyptic" and "post-apocalyptic" are the same concept, at what point do the concepts differ? Where are the borders of the category? Are "post-apocalyptic fiction" and "post-apocalyptic books" the same concept?

Flickr allows members to set limits on who can tag their photos, which restricts hospitality. Similarly, on LibraryThing, an account can be made private, disallowing the other to interlope into one's personal tags and removing the social aspect, a form of xenophobia. In some cases, discernment is necessary. On LibraryThing, "to-read" is tagged 572,795 times by 7,990 members (as of April 25, 2013). So, when searching for the books tagged as "toread" for personal purposes, the "to-read" lists for another 7,989 users would be retrieved as part of the same category unless the search is restricted to a personal library. Similarly, on Flickr, 3,846,694 photos were tagged with "me" and 258,050 of "Grandpa" (April 25, 2013). Without the exclusionary practice of search limit options, the re- trieval results would be overwhelming and inaccurate for the particular subject searching for "me."

\subsection{Extreme discernment}

The tagging environments examined here practice only minimal forms of discernment, which allow greater inclusivity of viewpoints, as well as the opportunity to be social and anti-social at the same time. In contrast, library standards practice an extreme form of discernment in standardization. The difference in discernment can be clearly seen between LibraryThing and the Library of Congress Subject Headings. Because of the difficulties of determining "aboutness" with fiction, typically fiction does not garner subject headings in most libraries; however, the Library of Congress does assign subject headings for some popular works. To illustrate this contrast, the LibraryThing tag cloud for The Da Vinci Code contains thousands of unique user tags in multiple languages, whereas LC, a decidedly non-hospitable environment according to Derrida's rubric, assigns six precoordinated headings in English:

\author{
Leonardo, da Vinci, 1452-1519 - Appreciation - \\ Fiction; \\ Art museum curators - Crimes against - Fiction; \\ Secret societies - Fiction; \\ Cryptographers - Fiction; \\ Grail - Fiction; \\ Paris (France) - Fiction; and \\ Mystery fiction (Library of Congress).
}

The Library of Congress Subject Headings (LCSH) are more objective, but missing much detail. Despite the controversy the book raised with the Catholic Church, the LCSH headings make no mention of religion. With tags, omissions caused by time, budget, and a desire for objectivity could be balanced to aid searching and to fulfill the advisory function of a catalog, particularly with works of fiction, where the "aboutness" of a work is multifaceted and subjective.

The hospitality of social tagging is of particular value in other venues, as well. In visual information retrieval, tagging can assist in description of the content or subjects of art or photographs, particularly when the art is contemporary or abstract, or if the description would be difficult or sound ridiculous. Would a museum's information professional assign Damien Hirst's The Physical Impossibility of Death in the Mind of Someone Living, unsophisticated terms such as "dead shark?" Users may be able to supplement the professional terminology with their own descriptions of indescribable, though in another context may be considered other. 


\subsection{Conclusion}

The gulf evident between tag clouds and controlled vocabulary demonstrates the limits of both hospitality and extreme discernment. The tag clouds are messy, loud, multicultural, inclusive, and obscene: more reflective of reality than the knowledge organization systems that purport to reflect it, but could be accused of being chaotic, inefficient, and relativistic. Derrida does not simply reverse the binary to privilege the unconditional form of hospitality over and above the traditional-conditional form of hospitality. Deconstruction celebrates ambiguity inherent in a concept, despite the risk involved, and the throng of concepts represented by tags demonstrates this. At the heart of the experience of hospitality is the concept of trust. As Aquinas (1981) argues, trust requires that we make virtuous presumptions about others' wills. In other words, we can never know with certainty, in advance, how others, even trusted others, will act—or tagwhich means we must hope that they will do the right thing. Both Flickr and LibraryThing attempt to coach in this direction with their provisional guidelines and minimal methods of mitigation.

This epistemic uncertainty illustrates the risk involved in any relationship of trust. The perfection of trust, of hospitality, according to Derrida must face this risk willing to suffer harm rather than commit preemptive acts of violence. The perfection of trust and hospitality must be continually articulated and perpetuated so as not to remain an abstract ideal. Is the hospitality allowed in social tagging enough to counteract the violence of bibliographic control? Or does bibliographic control's extreme discernment mitigate the unconditional hospitality of tagging? One cannot know in advance. The method of deconstruction, precisely to avoid missing the enigmatic other altogether and becoming a hostile and inferior interpretation of the other can only indicate or point in a preliminary fashion. Thus, deconstruction serves as a revisable way of pointing, of gauging the other's preliminary sense, while at the same time minimizing an uncritical lapse into some distorted conception of the other or belief in a universal. This 'pointing' is ultimately performative and should lead to a transformation of one's relation to the other. One must always negotiate with conditional forms of hospitality and conditional forms need to remain open to the absolute form so as not to devolve into unjust systems of power and control. To not violate social trust with commercial interests, to not erode the community of users with personal prejudice-to make impossible decisions a little more possible.

\section{References}

Aquinas, Thomas. 1981. The summa theologica (trans. Fathers of the English Dominican Province) Westminster, Md.: Christian Classics.

Berman, Sanford. 1993. Prejudices and antipathies: A tract on the LC subject heads concerning people. Jefferson, NC: McFarland \& Co.

Bowker, Geoff C. and Star, Susan. L. 1999. Sorting things out: Classification and its consequences. Cambridge, Mass.: MIT Press.

Critchley, Simon and Timothy Mooney. 1994. Deconstruction and Derrida. In Kearney, Richard ed., Continental philosophy in the 20 $0^{\text {th }}$ century. New York: Routledge.

Derrida, Jacques. 1976. Of grammatology, translated by Gayatri Chakravorty Spivak. 1 ${ }^{\text {st }}$ ed. Baltimore: Johns Hopkins UP.

Derrida, Jacques. 1988. Letter to a Japanese friend. In Wood, David and Bernasconi, Robert, eds., Derrida and differánce. Evanston, IL: Northwestern UP.

Derrida, Jacques and Dufourmantelle, Anne. 2000. Of bospitality: Anne Dufourmantelle invites Jacques Derrida to respond, translated by Rachel Bowlby. Stanford, Calif.: Stanford UP.

Fox, Melodie J. and Austin M. Reece. 2011. Which ethic? whose morality: An analysis of ethical standards for the organization of information. Knowledge organization 39: 377-83.

Kearney, Richard. 2004. Debates in continental philosophy: Conversations with contemporary thinkers. New York: Fordham UP.

Mai, Jens-Erik. 2004. Classification in context: Relativity, reality, and representation. Knowledge organization 31: 39-48.

Olson, Hope A. 1995. Qualitative 'versus' quantitative research: The wrong question. In Olson, Hope A. and Ward, Dennis B. eds., Connectedness: Information, systems, people, organizations; Canadian Association for Information Science, Proceedings of the 23rd Annual Conference / Association canadienne des sciences de l'information, travaux du 23 e congrès annuel. Edmonton, Alberta: School of Library and Information Studies, University of Alberta, pp. 40-9.

Olson, Hope A. 1997. The feminist and the emperor's new clothes: Feminist deconstruction as a critical methodology for library and information studies. $L i$ brary \& information science research 19: 181-98.

Olson, Hope A. 2002. The power to name: Locating the limits of subject representation in libraries. Boston: Kluwer Academic.

Wortham, Simon Morgan. 2010. The Derrida dictionary. New York: Continuum. 